\title{
Determination of Lower Acidity of Jet Fuel by Catalytic Thermometric Titration Using Paraformaldehyde as a Thermometric End- Point Indicator
}

ISSN: 2637-8035

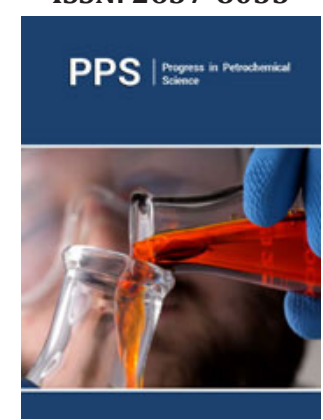

*Corresponding author: Quan Xi Zheng, Department of Aviation Oil, China Jian Qiang Hu, Department of Aviation Oil, China

Submission: April 07, 2020

Published: 佔July 20, 2020

Volume 3 - Issue 3

How to cite this article: Ji Xin Mao, Quan Xi Zheng, Xin Xu, Li Guo, Yong Liang Xin, et al. On the Regime of Ground Water during Filtration from Channels in the Soil Layer with the Underlying Pressure Horizon. Progress Petrochem Sci. 3(3). PPS. 000564. 2020.

DOI: $10.31031 /$ PPS.2020.03.000564

Copyright@ Quan Xi Zheng, This article is distributed under the terms of the Creative Commons Attribution 4.0 International License, which permits unrestricted use and redistribution provided that the original author and source are credited.
Ji Xin Mao ${ }^{1}$, Quan Xi Zheng ${ }^{1 *}$, Xin Xu ${ }^{1,2}$, Li Guo ${ }^{1}$, Yong Liang Xin ${ }^{1}$, Shi Zhao Yang ${ }^{1}$, Jian Jian Zhang ${ }^{1}$, Bing Hao Chen ${ }^{1}$ and Jian Qiang Hu${ }^{1 *}$

${ }^{1}$ Department of Aviation Oil, China

${ }^{2}$ State Key Laboratory of Tribology, China

\begin{abstract}
The effect of concentrations of titrant, delivery rates, stirring rates, and oil mass on catalytic thermometric titration for the determination of the lower acidity of jet fuel were investigated, using $\mathrm{KOH}$ in isopropanol and paraformaldehyde as titrant and a catalytic thermometric indicator respectively. The results show that paraformaldehyde used as a catalytic indicator exhibits strongly endothermic effects to reflect end point significantly. When the oil mass is from $10 \mathrm{~g}$ to $30 \mathrm{~g}$, the titration concentration is $0.01 \mathrm{~mol} / \mathrm{L}$ and the delivery rate is $1.0 \mathrm{~mL} / \mathrm{min}$ with moderate stirring, the tested acid numbers have good reproducibility and accuracy. The linear coefficient $\mathrm{R}^{2}$ of the fitting curve is 0.995 . Using benzoic acid as a standard acid with concentration of $0.0105 \mathrm{mg} \mathrm{KOH} / \mathrm{g}$ to verify the accuracy of catalytic thermometric titration, the verified acid number is $0.0115 \mathrm{mg} \mathrm{KOH} / \mathrm{g}$ and basically consistent with the actual acid number, indicating that catalytic thermometric titration has good agreement with standard potentiometric titration methods and can be used for determination of acid number of jet fuels. It can accurately determine the acid number of jet fuel as low as $0.015 \mathrm{mg} \mathrm{KOH} / \mathrm{g}$ or even lower at optimized test conditions. The procedure is fast, easy to use, accurate, and highly reproducible to measure lower acidity in jet fuel. It is very suitable for the routine process and quality control of many types of oils.
\end{abstract}

Keywords: Acidity; Jet fuel; Catalytic thermometric titration; Paraformaldehyde

\section{Introduction}

As an important quality control index to evaluate corrosion, especially for fuel oil, aviation oil, and hydraulic oil, the acidity of oils is applied to estimate the properties and deterioration of oils during usage and storage [1-3], which is determined with the standard methods based either on visual indicators titration or potentiometric titration [4-7]. However, accuracy of visual titration is strongly influenced by the skills and color perception of the analyst, and especially differential color perception of analysts is considerable for coloured oils. Potentiometric titration, especially for oils containing trace weak polyacids, is subject to the noxious influence of the sample solutions and is always unreliable because of the weak change of potential during acid-base neutralization titration, which results in difficult detection of end-point and repeatability. In order to achieve more fast and efficient determination of the end-point in titrations, there is increasing attention for a simple, fast, accurate, and precise automatic titrimetric operation that is substantially independent of analysts' skills and suitable for routine process and quality control.

As a new method, catalytic thermometric titration has several attractive features: [1] the apparatus is simple, and all that required is a temperature measuring probe such as a thermometer or a thermistor as the sensing element; [2] the thermometric probes are inert to most solutions, and temperature changes in highly colored can be detected easily; [3] the 
range of indication reaction is unlimited because all of reactions are accompanied with temperature changes, the magnitude of which can be adjusted by changing reagents' concentrations [8-11]. The basic principle of this method is catalytic initiation of an exothermic or endothermic reaction with an excess of titrant, as a consequence, the end-point can be indicated by obvious temperature changes of the solution [8-15]. It has been successfully applied for determining acidic substances in aluminum ion concentration of waste water and vegetable oils [16-19]. However, as so far, there are few reports on application of catalytic thermometric titration on lower acidity of jet fuels.

When small amounts of weak acidic species are titrated in nonaqueous solution with a titrant of strong alkali, the heat produced from the neutralization reactions may be quite small and easy to be confused by solvent evaporation and the mixing heat of the titrant with sample solution [4-7]. If the special thermometric indicator is added to sample solution, excess hydroxide ions would react quickly with them in endothermic or exothermic reactions, the end-point can be easily determined by temperature increase or decrease of the solution $[20,21]$. However, practical experience has demonstrated that the endpoint in thermometric titration showed excessive rounding, with consequent loss of precision and accuracy for some oils with lower acidity, such as aviation oil, hydraulic oil and fuel oils. Many studies have shown that titration error or the sharpness of the endpoint can be related to the concentration and delivery rate of titrant, volumes, and types of thermometric indicator [22-27]. In our previous studies [9,10], the trace water in jet fuels, as well as the acidity of several coloured oils, could be accurately and rapidly determined by catalytic thermometric titration using the mixture of acetone and chloroform as the endpoint indicator. In this paper, we report herein our results on the determination of the lower acidity of jet fuels with catalytic thermometric titration employing paraformaldehyde as the endpoint indicator, which exhibits strongly endothermic effects to reflect end point significantly and can determinate much more lower acidity than ASTM thermometric titration, and compared with potentiometric titration, the accuracy and repeatability of the thermometric titration is further investigated.

\section{Materials and Methods}

\section{Materials}

Paraformaldehyde, potassium hydroxide and isopropanol were of analytical reagent quality. A $0.10 \mathrm{~mol} / \mathrm{L}$ potassium hydroxide isopropanol solution was prepared and standardized with potassium hydrogen phthalate by the usual procedures. The jet fuel NO.3 was purchased from Sinopec Tianjin Shihua. Standard acid solution was prepared from approximately $37.8 \mathrm{mg}$ benzoic acid dissolved with $250 \mathrm{~mL}$ isooctane, and acid value of standard acid is $0.10 \mathrm{mg} \mathrm{KOH} / \mathrm{g}$.

\section{Apparatus}

In thermometric titration, two motor-driven micrometer syringes were employed to add the titrant to samples at a constant delivery rate, and a magnetic stirrer was provided to dissolve oil solutions, the temperature changes were detected by locating the thermistor in one arm of a Wheatstone bridge and were recorded with a strip chart recorder. At the end of each titration, sample and titration data were automatically sent for identification and computation, the acidity of oil samples was obtained from autocalculation. In potentiometric titration, a $\mathrm{pH}$ probe containing both a glass and a reference electrode in the same body was employed.

\section{Methods}

In visual titration, the amount of oil was chosen in accordance with the ASTM D974 method, 8g oil samples was dissolved in $125 \mathrm{~mL}$ ethanol solvent, $0.5 \mathrm{~mL} 2 \%$ ethanol solution of alkali blue $6 \mathrm{~B}$ was added and the solution was titrated with $0.1 \mathrm{~mol} / \mathrm{L} \mathrm{KOH}$ ethanol solution. In the case of catalytic thermometric titration, oil samples were accurately weighed into clean, dry $125 \mathrm{~mL}$ silvered Dewar flask, then $25 \mathrm{~mL}$ acetone and $4 \mathrm{~mL}$ chloroform were homogenized by using a magnetic stirrer. The $0.10 \mathrm{~mol} / \mathrm{L} \mathrm{KOH}$ titrant solution is added at a constant delivery rate of $0.5 \mathrm{~mL} / \mathrm{min}$ to the stirred solution. End-points were determined using a peak-picking algorithm applied to the second derivative curve computed from the smoothed temperature data. During titration, there is a blank to be determined. The blank is a summation of all delays inherent in the titration solution under defined experimental conditions. These delays include contributions from kinetics of the chemical reaction between titrant and titrant, sensor response, mixing inefficiencies, electronic transfer, and computation of data. The volumes of the titrant obtained in the blank solution titration were subtracted from those the initial titration data of oil samples. Each titration experiments were performed in four times. In the case of potentiometric titration, except for oil samples were dissolved in $125 \mathrm{~mL}$ of the solvent mixture (isopropanol and toluene), the oil samples stirring, dissolution and titrant addition procedures were employed accordance with the ASTM D664 method.

\section{Results and Discussion}

\section{Effect of concentrations of titrant on thermometric titration}

As listed in Table 1, concentrations of the titrant have great influence on determination results of thermometric titration. The concentration of the titrant is high, and the consumption of the titrant volume is small. In contrast, the concentration of the titrant is low, and the consumption of the titrant volume is large. The thermometric titration curves obtained from titrant with different concentrations are shown in Figure 1, from which we can see clearly that there are obvious temperature changes in thermometric 
titration curves, where the second-derivative plot is presented along with the solution temperature plot. Due to the lower acid number in jet fuel, which is less than $0.015 \mathrm{mg} \mathrm{KOH} / \mathrm{g}$, and a greater deviation caused by the higher concentration of the titrant, the $0.01 \mathrm{~mol} / \mathrm{L}$ of titrant is used in all subsequent experiments in order to obtain more precise acid number.

Table 1: The determination results of different concentrations of titrants.

\begin{tabular}{|c|c|c|c|}
\hline Titrant Concentration $/ \mathrm{mol} \cdot \mathrm{L}^{-1}$ & Oil mass $/ \mathrm{g}$ & Titrant Consumption $/ \mathrm{mL}$ & Acid Number $/ \mathrm{mg} \mathrm{KOH} \cdot \mathrm{g}^{-1}$ \\
\hline 0.0505 & 10 & 0.126 & 0.0357 \\
\hline 0.0505 & 10 & 0.134 & 0.038 \\
\hline 0.0505 & 10 & 0.143 & 0.0405 \\
\hline 0.0205 & 10 & 0.253 & 0.0291 \\
\hline 0.0205 & 10 & 0.275 & 0.0316 \\
\hline 0.0205 & 10 & 0.265 & 0.0305 \\
\hline 0.01046 & 10 & 0.462 & 0.0271 \\
\hline 0.01046 & 10 & 0.451 & 0.0265 \\
\hline
\end{tabular}
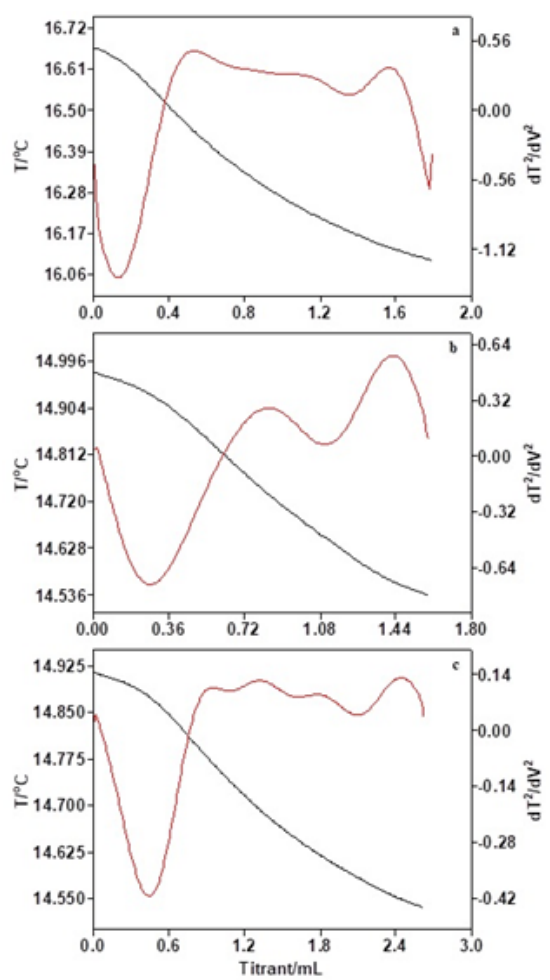

Figure 1: Thermometric titration curves of different concentrations of titrants (a: $0.05 \mathrm{~mol} / \mathrm{L}, \mathrm{b}$ : $0.02 \mathrm{~mol} / \mathrm{L}, \mathrm{c}$ : $0.01 \mathrm{~mol} / \mathrm{L}$ ).

\section{Effect of delivery rates on thermometric titration}

Table 2: The determination results of different delivery rates.

\begin{tabular}{|c|c|c|c|}
\hline Oil mass/g & Titrant Consumption/mL & Acid Number/mg KOH·g-1 & RSD(n=3) \\
\hline 5 & 0.35 & 0.00736 & $8.60 \%$ \\
\hline 10 & 0.45 & 0.00851 & $2.80 \%$ \\
\hline 15 & 0.525 & 0.00861 & $2.90 \%$ \\
\hline 25 & 0.58 & 0.00807 & $2.60 \%$ \\
\hline 30 & 0.66 & 0.00833 & $1.50 \%$ \\
\hline
\end{tabular}

As Table 2 and Figure 2 show, when the delivery rate of smooth without an obvious inflection point. When the delivery the titrant is $0.5 \mathrm{~mL} / \mathrm{min}$, the thermometric titration curve is rate is between $1.0 \mathrm{~mL} / \mathrm{min}$ and $0.2 \mathrm{~mL} / \mathrm{min}$, there are obvious 
temperature changes in thermometric titration curves, where the second-derivative plot with sharp peak is presented along with the solution temperature plot, and the results are accurate and repeatable. Therefore, the delivery rate of titrant plays an important effect on the determination results for thermometric titration, and according to the smallest relative standard deviation (RSD) obtained in the result of titrant consumption, the $1.0 \mathrm{~mL} / \mathrm{min}$ of delivery rate is optimal.

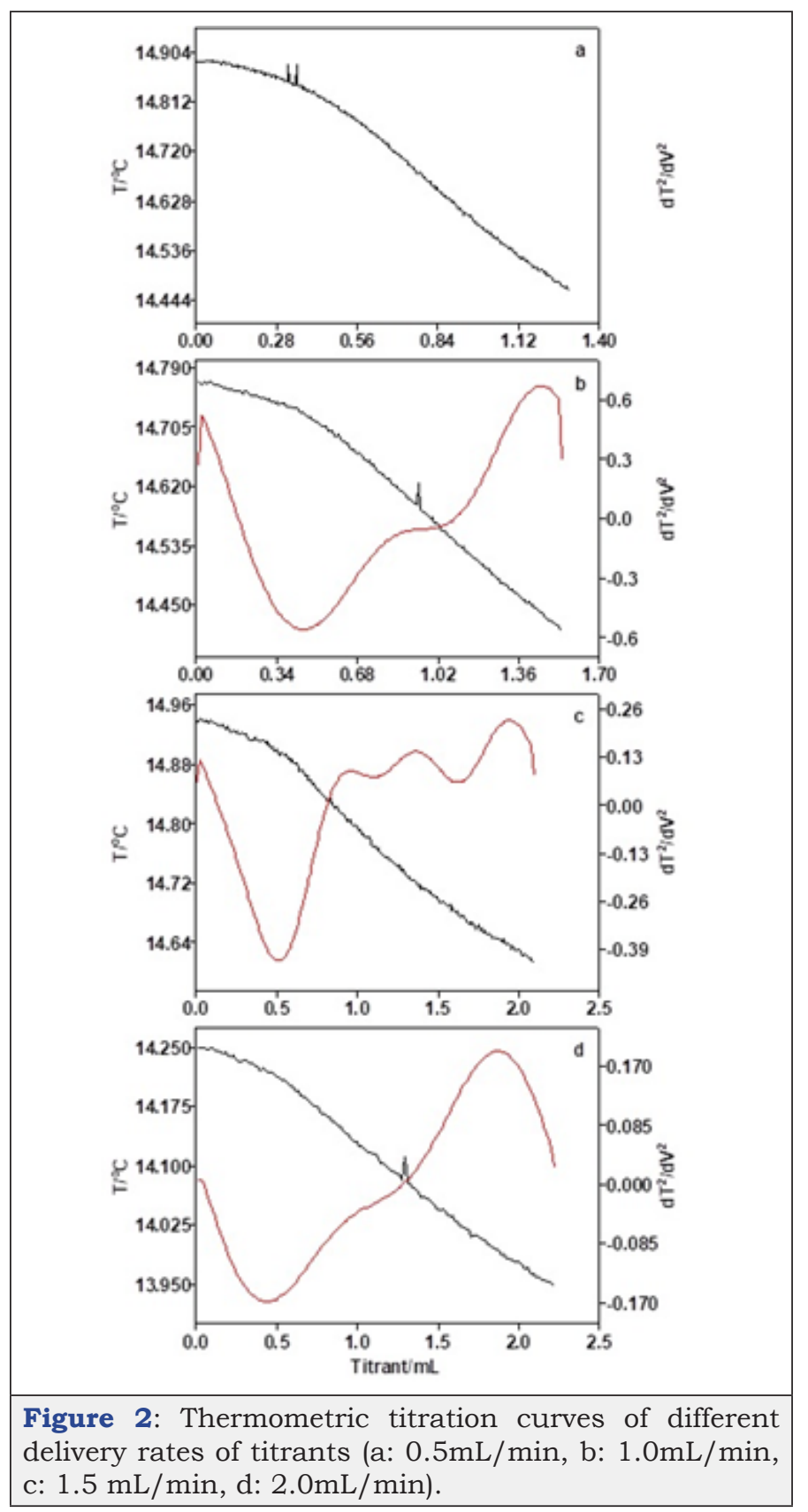

\section{Effect of stirring rates on thermometric titration}

As Figure 3 exhibits, only when the stirring rate is moderate, there are obvious temperature changes in thermometric titration curves, where the second-derivative plot with sharp peak is presented along with the solution temperature plot, and the results are accurate and repeatable. While, when the stirring rate is small, most of paraformaldehyde powders are deposited at the bottom of the titration beaker, which could not be catalyzed by titrant to process endothermic reaction, so that the temperature of the titration system remained basically unchanged. And when the stirring rate is high, the temperature sensor is unable to detect the temperature of the titration system since eddy currents are produced in the titration solution due to the excessive speed of the rotor stirring. Therefore, the moderate stirring rate is optimal.

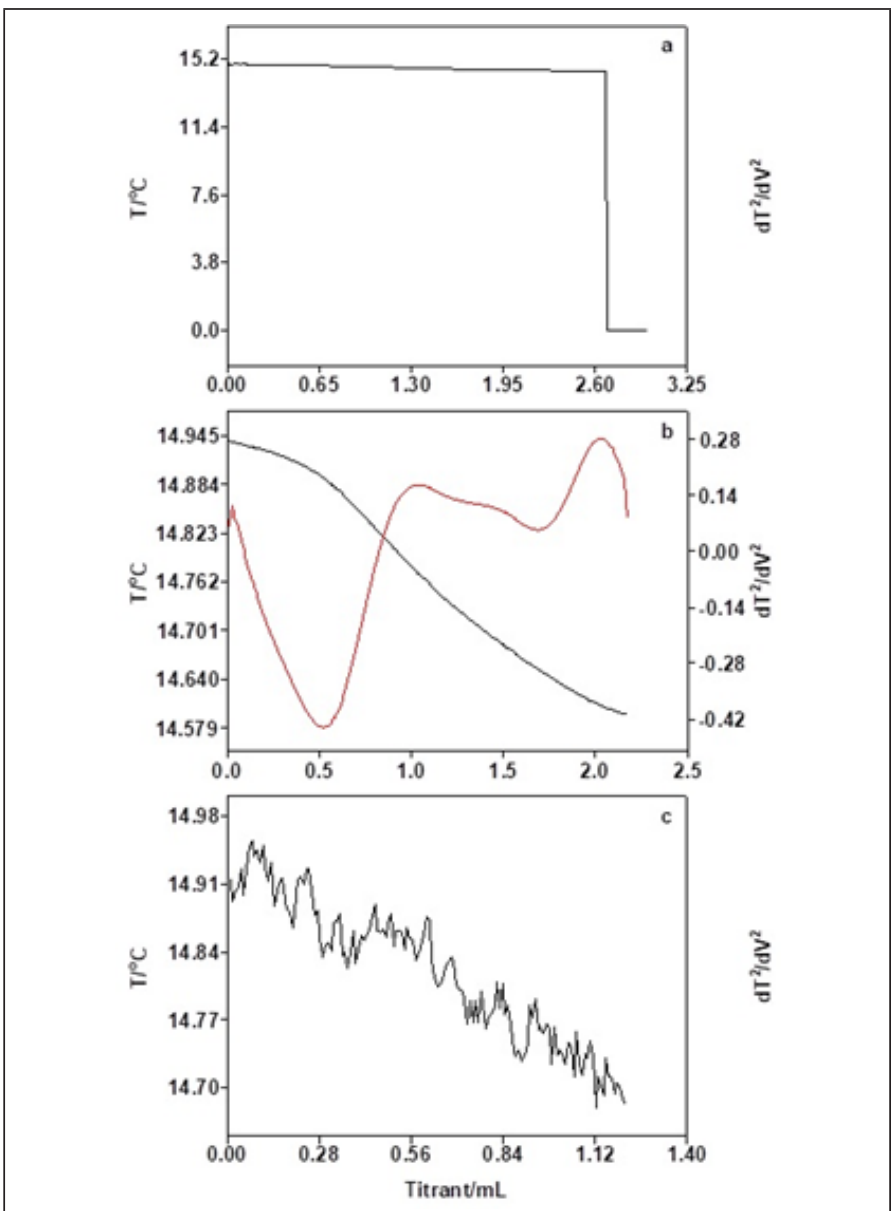

Figure 3: Thermometric titration curves of different stirring rates (a: low, b: moderate, c: fast).

\section{Effect of oil mass on thermometric titration}

As Table 3 and Figure 4 show, when the oil mass is 5.0g, the temperature change of thermometric titration curve is obvious and the end-point of titration is easily judged. However, due to the small oil mass and the lower acidity, the titration system is relatively vulnerable to other factors, and the repeatability of titration results is not stable. When the oil mass is between $10.0 \mathrm{~g}$ and $30.0 \mathrm{~g}$, the thermometric titration curves are smooth with obvious titration end-point, and the second-derivative plots are presented along with the solution temperature plot, which have sharp peak and obvious titration end-point. As Table 3 exhibits, the results of acid number are basically the same with reasonable RSD value. As Figure 5 shows, the coefficient of correlation (R2) for the linear calibration 
curve for different oil mass is found to be 0.9949 . The results show that better accuracy and repeatability of tested acid number can be obtained, when the concentrations of titrant, delivery rates, stirring

Table 3: The determination results of different oil mass. rates, and oil mass are $0.01 \mathrm{~mol} / \mathrm{L}, 1.0 \mathrm{l} / \mathrm{min}$, moderate and $10-30 \mathrm{~g}$, respectively.

\begin{tabular}{|c|c|c|c|}
\hline Oil mass/g & Titrant Consumption/mL & Acid Number $/ \mathbf{m g ~ K O H \cdot g - 1}$ & RSD(n=3) \\
\hline 5 & 0.35 & 0.00736 & $8.60 \%$ \\
\hline 10 & 0.45 & 0.00851 & $2.80 \%$ \\
\hline 15 & 0.525 & 0.00861 & $2.90 \%$ \\
\hline 20 & 0.58 & 0.00807 & $2.60 \%$ \\
\hline 30 & 0.66 & 0.00833 & $1.50 \%$ \\
\hline
\end{tabular}
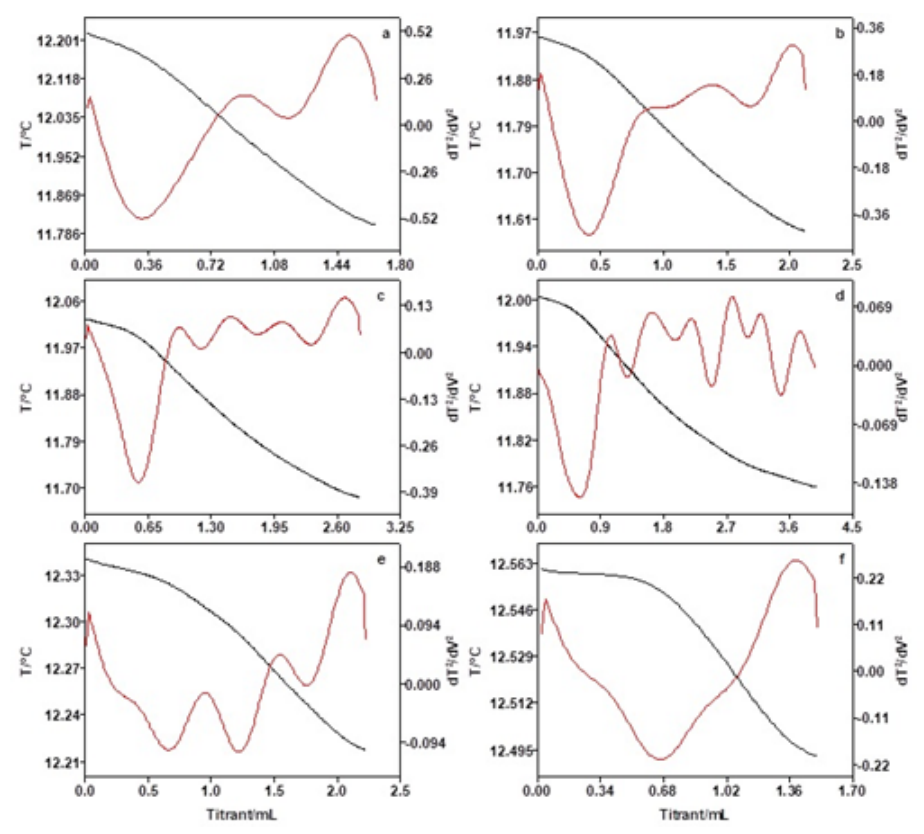

Figure 4: Thermometric titration curves of different oil mass (a: $5 \mathrm{~g}, \mathrm{~b}: 10 \mathrm{~g}, \mathrm{c}: 15 \mathrm{~g}, \mathrm{~d}: 20 \mathrm{~g}$, e: $25 \mathrm{~g}$, f: $30 \mathrm{~g}$ ).

\section{Thermometric titration in standard acid samples}

In order to testify the accuracy of the method of catalytic thermometric titrimetry, different mass of benzoic standard acid samples was investigated, and the results are listed in Table 4. The coefficient of correlation (R2) for the linear calibration curve was found to be 0.9924 , which was shown in Figure 6. We can see clearly that the acid numbers of three standard acid samples were very similar to real acid number $(0.10 \mathrm{mg} \mathrm{KOH} / \mathrm{g})$ with low RSD. These observations confirm that thermometric titrimetry is an accurate and highly reproducible method, which was easy to determine acid number of colored or additive-containing petroleum oils in titrations.

Table 4: The determination results of different mass of standard acid samples.

\begin{tabular}{|c|c|c|c|}
\hline Standard acid/mL & Titrant consumption/mL & Acid number/mg KoH·g-1 & RSD(n=3)/\% \\
\hline 10 & 0.375 & 0.0112 & 0.71 \\
\hline 20 & 0.528 & 0.012 & 3.1 \\
\hline 30 & 0.653 & 0.0114 & 5.4 \\
\hline
\end{tabular}

\section{Comparison of thermometric and potentiometry titration in jet fuel NO.3}

Table 5: Results from the acid number of oil samples by thermometric, potentiometry and visual titrimetry.

\begin{tabular}{|c|c|c|c|c|}
\hline & Titrant Concentration/mol-L $\mathbf{L}^{-\mathbf{1}}$ & Oil mass/g & Titrant Consumption/mL & Acid Number/mg KOH·g-1 \\
\hline \multirow{3}{*}{ Thermometric Titrimetry } & 0.01046 & 20 & 0.58 & 0.00807 \\
\cline { 2 - 5 } & 0.01046 & 20 & 0.59 & 0.00851 \\
\hline \multirow{2}{*}{ Potentiometric Titrimetry } & 0.01046 & 103.2 & 1.43 & 0.00861 \\
\cline { 2 - 5 } & 0.01046 & 100.5 & 1.36 & 0.00736 \\
\hline
\end{tabular}




\begin{tabular}{|l|c|c|c|c|}
\hline \multirow{2}{*}{ Visual Titrimetry } & 0.01046 & 102.3 & 1.45 & 0.0081 \\
\cline { 2 - 5 } & 0.01046 & 100.1 & 1.4 & 0.0078 \\
\hline
\end{tabular}

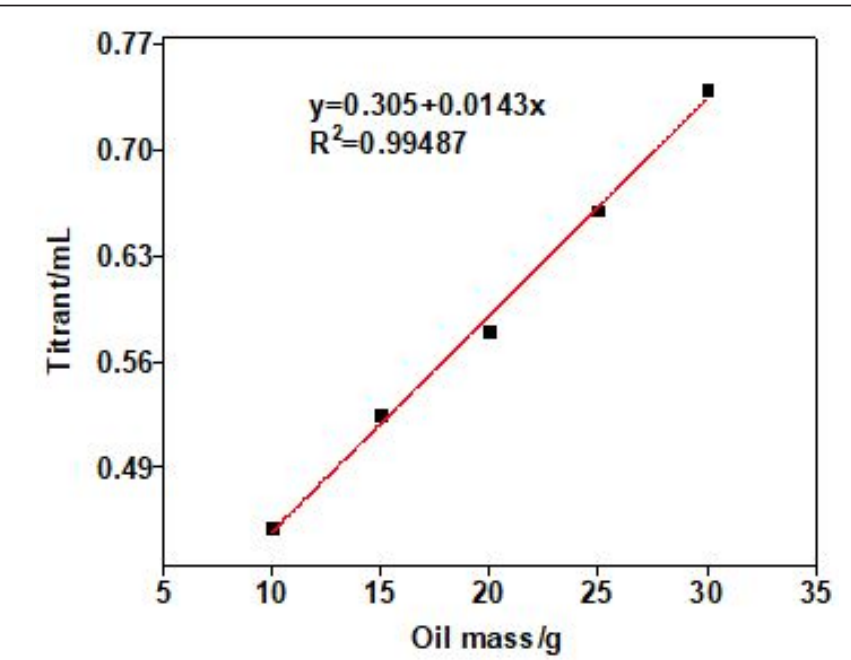

Figure 5: Linear regression equation for different oil mass.

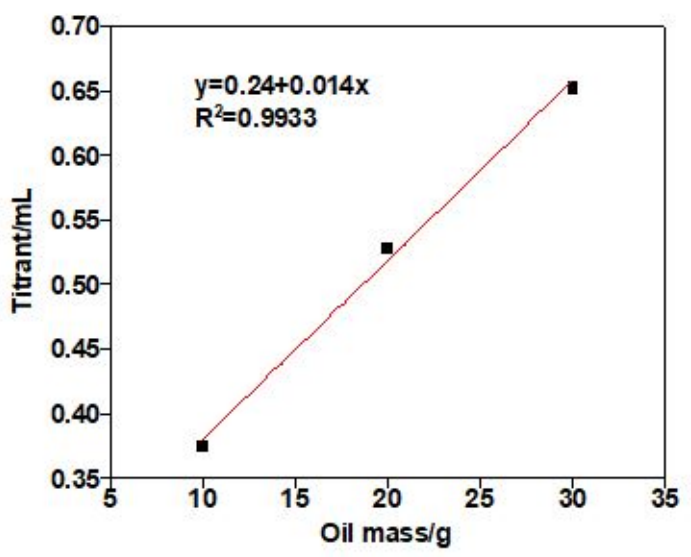

Figure 6: Linear regression equation for benzoic acid samples.

The titration of jet fuel NO.3 is investigated by catalytic thermometric titrimetry, employing paraformaldehyde as endpoint indicator. By comparison, potentiometric titration is employed to analyze the same oil sample. The acid number of jet fuel NO.3 obtained from thermometric, potentiometry and visual titrimetry titration are shown in Table 5, from which we can see clearly that the acid numbers of jet fuel NO.3 obtained from catalytic thermometric titrimetry are basically consistent with potentiometry and visual titrimetry with less error.

\section{Conclusion}

The catalytic thermometric titration is a fast, easy to use, accurate, and highly reproducible method to determine lower acidity in jet fuels, using paraformaldehyde as the end-point indicator. Paraformaldehyde used as the end-point indicator can exhibit strongly endothermic base catalyzed reaction in thermometric titration, which has good agreement with standard acid samples. It can accurately determine the acid number of jet fuels as low as $0.015 \mathrm{mg} \mathrm{KOH} / \mathrm{g}$ or even lower at optimized test conditions. The procedure is fast, easy to use, accurate, and highly reproducible to measure lower acidity in jet fuel. It is very suitable for the routine process and quality control of many types of oils.

\section{References}

1. Shinde H, Bewoor A (2018) Capacitive sensor for engine oil deterioration measurement. AIP Conference Proceedings 1943(1): 020099.

2. Cui D, Wang Q Wang P, Chi MS, Pan S, et al. (2018) A comparison of the compositions of acidic and basic fractions in $<300^{\circ} \mathrm{C}$ fractions from six Chinese shale oils. Fuel 211: 251-260.

3. He, QJ (2013) Analysis of acid number in crude oil and petroleum product and acid distribution. Guangzhou Chemical Industry 5: 17-20.

4. Lima RAC, Almeida LF, Lyra WS, Siqueira LA, Gaião EN, et al. (2016) Digital movie based on automatic titrations. Talanta 147: 226-232.

5. Kahlert H, Meyer G, Albrecht A (2016) Colour maps of acid-base titrations with colour indicators: how to choose the appropriate indicator and how to estimate the systematic titration errors. Chem Texts 2: 7.

6. Stuart BS, Ferrell JR (2016) Determination of carbonyl groups in pyrolysis bio-oils using potentiometric titration: review and comparison of methods. Energy Fuels 30(2): 1071-1077.

7. Yu K, Kumar N, Aho A, Roine J, Heinmaa I, et al. (2016) Determination of acid sites in porous aluminosilicate solid catalysts for aqueous phase reactions using potentiometric titration method. Journal of Catalysis 335: 117-124.

8. Phansi P, Danchana K, Cerdà V (2017) Kinetic thermometric methods in analytical chemistry. TrAC Trends in Analytical Chemistry 97: 316-325.

9. Hu JQ Zhang JJ, Yang SZ, Xin YL, Guo L, et al. (2017) Thermometric titration for rapid determination of trace water in jet fuel. Journal of Specroscopy 21: 1-5.

10. Hu JQ, Xin YL, Yang SZ, Zhang JJ, Guo L (2017) The determination of lower acidity in several coloured oils by catalyzed thermometric titration. Petroleum Chemistry 57: 1099-1104.

11. Azevedo MCC, Cavaleiro AMV (2012) The acid base titration of a very weak acid: boric acid. Journal of Chemical Education 89(6): 767-770.

12. Bastos FA, Khan S, Simões EH, Teixeira CA, Tubino M (2013) Thermometric quantitative selective analysis of sodium methoxide in methanol industrial solutions. Journal of the Brazilian Chemical Society 24(8): 1380-1384.

13. Relli D, Vincent MT (2018) Thermometric titration study of acetaminophen and sodium hypochlorite. Ohio Dominican University, Ohio.

14. Barin JS, Tischer B, Oliveira AS, Wagner R, Costa AB, et al. (2015) Infrared thermal imaging: a tool for simple, simultaneous, and high throughput enthalpimetric analysis. Analytical Chemsitry 87(24): 12065-12070.

15. Gumel AM, Annuar MSM, Heidelberg T, Chisti Y (2011) Thermo-kinetics of lipase-catalyzed synthesis of 6-0-glucosyldecanoate. Bioresource Technology 102(19): 8727-8732.

16. Tao L, Sun H, Gong Y (2012) Determination of total acidity and aluminumion concentration in wastewater of aluminum profile surface treatment by thermometric titration. Metallurgical Analysis 32: 46-50.

17. Jiang T, Zhan HY, Wang LJ (2011) Experiments and applications of automatic temperature titrator in the control and analysis of alumina production process. Light Metals 46: 22-25. 
18. Thomas KS (2003) Analysis of FFA in edible oils by catalyzed end point thermometric tirimetry (CETT). Journal of the American Oil Chemists Society 80: 21-24.

19. Carneiro JD, Feres MA, Godinho ES (2002) Determination of the acidity of oils using paraformaldehyde as a thermometric end-point indicator. Journal of the Brazilian Chemical Society 13(5): 692-694.

20. Cerdà V, González A, Danchana K (2017) From thermometric to spectrophotometric kinetic-catalytic methods of analysis: A Review. Talanta 167: 733-746.

21. Jharimune S, Sathe AA, Riou RM (2018) Thermochemical measurements of cation exchange in CdSe nanocrystals using isothermal titration calorimetry. Nano Letters 18(11): 6795-6803.

22. Rivera MRD, Matos JS, Socorro F (2008) Study of the stirring effect in ASTM 2277-205 isothermal titration calorimetric. Journal of Thermal Analysis and Calorimetry 92: 79-82.
23. Demoz A, Mikula RJ (2011) A thermometric indicator method as a replacement for the filter paper spot test in the titration of clays using methylene blue. Engineering Geology 117(1-2): 12-16.

24. Luk HN, Peng HY, Han YW, Lin CK, Lin WD, et al. (2018) Detection of acetaminophen using cyclic voltammetry on $\mathrm{MnFe}_{2} \mathrm{O}_{4} /$ polyaniline. Journal of the Chinese Chemical Society 66(1): 1-6.

25. Gu QJ, He ZH, Pan QX, Lin ZY, Sun J, et al. (2019) The steric hindrance controlled [2] pseudorotaxanes constructed by V-type stilbene dyes $\subset \mathrm{CB}$ [7]. Supramolecular Chemistry 31(2): 1-11.

26. Hidayat A, Sutrisno B (2018) Free fatty acids esterification on palm oil sludge using zirconia-supported indonesia natural zeolite as heterogeneous catalyst. Oriental Journal of Chemistry 34(5): 2464.

27. Čobanov I, Šarac B, Medoš Z, Vraneš M, Gadžurić S, et al. (2018) Effect of cationic structure of surface active ionic liquids on their micellization: A thermodynamic study. Journal of Molecular Liquids 271: 437-442.

For possible submissions Click below:

Submit Article 